\title{
Micromachined Microwave Planar Spiral Inductors and Transformers
}

\author{
Renato P. Ribas, Jérome Lescot, Jean-Louis Leclercq, Jean Michel Karam, Member, IEEE, and Fabien Ndagijimana
}

\begin{abstract}
A new micromachined planar spiral inductor, with the strips suspended individually, has been fabricated in standard GaAs high electron-mobility transistor monolithic-microwave integrated-circuit technology through maskless front-side bulk micromachining. The electronic compatibility, the use of industrial integrated-circuit production lines, the straightforward and low-cost additional procedure for structure releasing, and the very short etching time required to do such are the principal features related to such a novel inductor structure. Moreover, the air-gap layer created underneath the device and between the strips significantly reduces shunt and fringing parasitic capacitances, consequently increasing the performance and operating frequency range. Experimental measurements, carried out up to $15 \mathrm{GHz}$, before and after micromachining, showed for a 12-nH inductor an increase of the maximum $Q$ factor from 5 (at $3 \mathrm{GHz}$ ) to about 20 (at $7 \mathrm{GHz}$ ), while the self-resonant frequency was shifted from 5 to $13 \mathrm{GHz}$. Furthermore, a structure with two interleaved spiral inductors, in a 1:1 transformer-like configuration, was also fabricated, and its performance was verified as well in order to demonstrate the promising performance improvements provided by the proposed device. Finally, heating and mechanical characteristics associated with freestanding microstructures are briefly evaluated using finite-element method simulations.
\end{abstract}

Index Terms-Inductors, micromachined devices, micromachining, MMIC, planar transformers, suspended microstrip.

\section{INTRODUCTION}

$\mathbf{T}$ HE increasing interest in monolithic microwave integrated circuits (MMIC's) today is due to several emergent applications, such as mobile wireless communication, satellite reception [global positioning system (GPS) and digital broadcasting satellite (DBS)], millimeter-wave radiometers, and automotive systems. Small size and weight, elimination of wire bonding, low power consumption, volume manufacturability, reliability, and reproducibility are some of numerous advantages of MMIC's in respect to discrete and hybrid components.

Manuscript received October 23, 1998. The work of R. P. Ribas was supported under a Fundação Coordenação de Aperfeiçoamento de Pessoal de Nível Superior Scholarship.

R. P. Ribas and J. M. Karam are with the Techniques de l'Informatique de la Microelectronique pour l'Architecture d'ordinateurs Laboratory, F38031 Grenoble, France (e-mail: Renato.Ribas@imag.fr).

J. Lescot was with the Laboratoire d'Electromagnétisme Microondes et Optoélectroniques, F38016 Grenoble, France. He is now with Simplex, Sunnyvale, CA 94085 USA.

J. L. Leclercq is with the Laboratoire d'Electronique, Optoelectronique et Microsystemes, Ecole Centrale de Lyon, F69131 Ecully, France (e-mail: Leclercq@ec-lyon.fr).

F. Ndagijimana is with the Laboratoire d'Electromagnétisme Microondes et Optoélectroniques, Ecole Centrale de Lyon, F69131 Grenoble, France.

Publisher Item Identifier S 0018-9480(00)06532-7.
Despite recent advances in microelectronics processes, with the increasing cutoff frequency of silicon-based transistors (at gigahertz band) and level of integration of most GaAs integrated-circuit (IC) processes, passive components, such as transmission lines, planar inductors, and transformers still suffer from low performance at high frequencies due to losses and parasitic effects [1].

Therefore, a great effort has been done in order to improve the performance of such components, in particular, using the low-cost and mature silicon technology, by considering, e.g., multilevel interconnect processes, higher substrate resistivity, $\mathrm{Cu}$ metallization instead of $\mathrm{Al}$, and freestanding devices [2]-[11]. Micromachining techniques, which are widely used to build monolithic integrated sensors and actuators [12], have also been proven very useful to enhance microwave passive devices through the construction of membrane-supported and shielded planar lumped elements [7]-[11]. However, specific processes or additional masking steps are usually required, and the electronic integration is somewhat compromised. The front-side bulk micromachining, on the other hand, seems to be the most efficient way to microelectromechanical system (MEMS) design, in terms of fabrication cost and electronic compatibility, since a straightforward maskless post-process etching is enough to release the structures [9]-[11].

This micromachining approach has been successfully used in a standard GaAs high electron-mobility transistor (HEMT) technology from Philips Microwave Limeil (PML), Limeil, France, and presents as the principal features the very small "open areas" (stack of dielectric and passivation openings needed to etch away the substrate material), the numerous suitable etchants without selective and preferential etching constraints, the compatibility to MMIC design, and all characteristics related to the GaAs material, i.e., high-temperature operation, piezoelectric effect, high thermal resistivity, high Seebeck coefficient, and so on [13].

In this paper, micromachined planar spiral inductors and transformers are presented. The open-area dimensions used herein for micromachining purposes allowed the construction of these devices with each spiral segment suspended individually. Such a novel structure is easier to fabricate than the well-known membrane-supported version because of the short etching time required. Furthermore, besides shunt capacitances, fringing parasitic effects, very critical in planar spiral transformers [14], [15], are also significantly reduced. The respective lumped equivalent models, analytical formulations, experimental measurements, heating, and mechanical characteristics are discussed in following sections. 


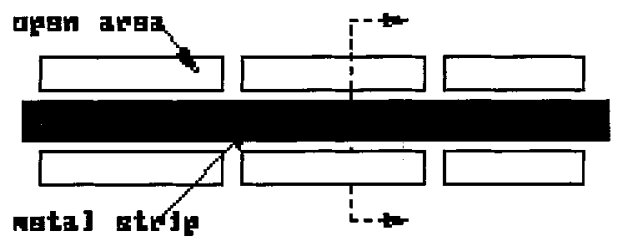

past-pucaso wat atching $1+1+1++|1++|+1++\mid 1+t+1 d$
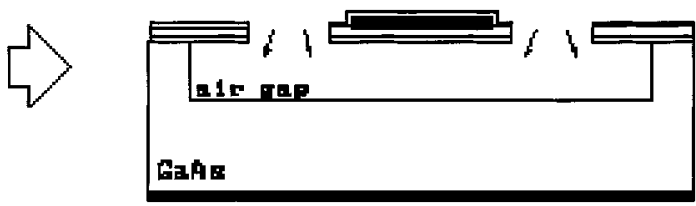

(a)
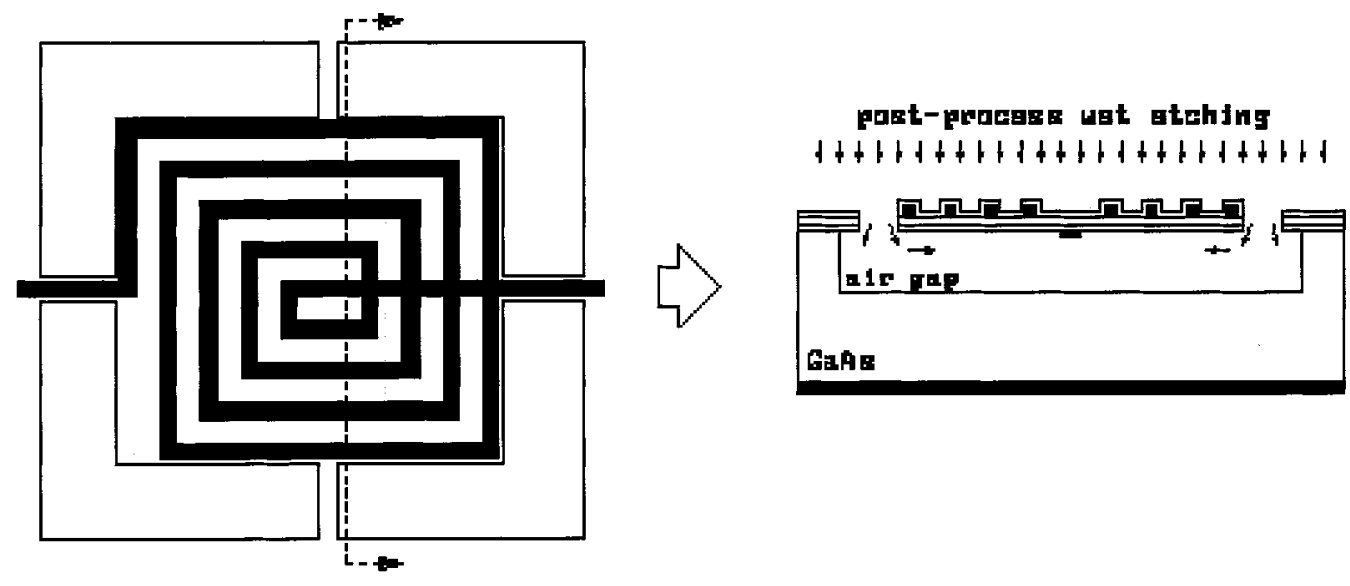

(b)
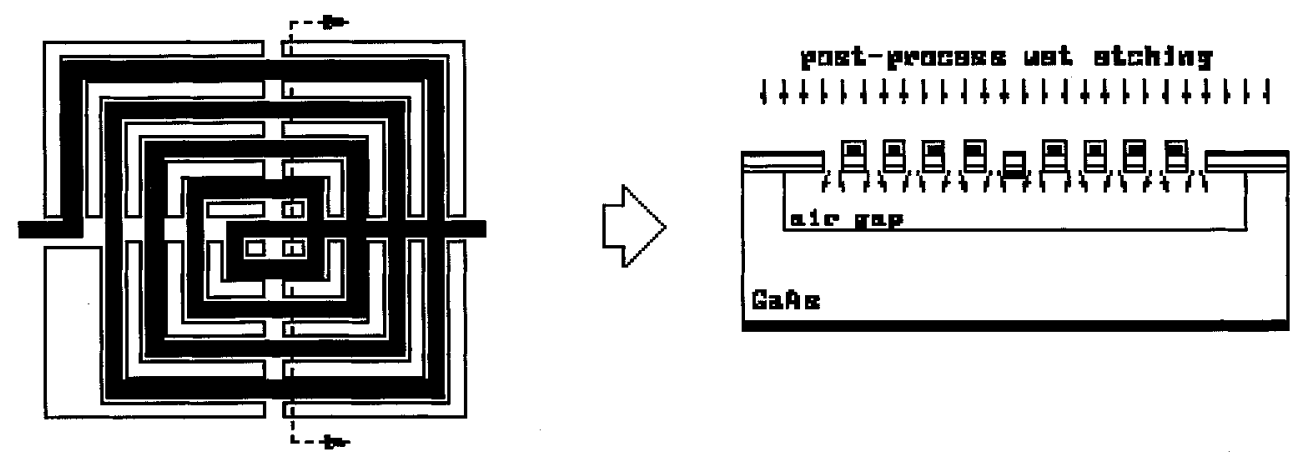

(c)

Fig. 1. Front-side bulk micromachined structures. (a) Suspended microstrip line. (b) Membrane-supported inductor. (c) Planar spiral inductor with strips suspended individually.

\section{MICROMACHINING DESCRIPTION}

The front-side bulk micromachining approach relies on a post-process wet etching, with no modification in the standard IC fabrication, no additional masking, and no influence on the unconcerned electronic parts. Uncovered substrate surface regions (open areas), necessary to etch away portions of the bulk material, are created by stacking dielectric and passivation openings. As a result, bridges, cantilevers, membranes, and other geometries are easily constructed through the appropriate placement of open areas in the layout. The target technology is the 0.2- $\mu \mathrm{m}$ GaAs HEMT D02AH process from PML, which provides a $100-\mu \mathrm{m}$-thick GaAs substrate with backside ground plane for microstrip design [16]. The layout top view and cross section of a freestanding line is shown in Fig. 1(a). Note that the minimum open area width allowed with this process is equal to $4 \mu \mathrm{m}$.

Two types of suspended planar spiral inductors are possible using this approach: the membrane-supported version [see Fig. 1(b)], as presented by Chang et al. [9] in standard CMOS, and a novel structure with the strips suspended individually, taking advantage of the small open-area dimensions. As illustrated in Fig. 1(c), the etching time needed for complete suspension of such new version depends only on the linewidth and not on the total structure size or number of spiral turns. Large membranes, otherwise generally demand special attention in the etching procedures to avoid possible damages in the pad metallization and passivation layers caused by excessive etchant time exposure. Moreover, the elimination of the dielectric layers between the spiral wires contributes even more to 
reduce the fringing capacitances. However, the heat dissipation represents an important drawback, as discussed in Section V.

After IC fabrication, a pre-cleaning step is applied on dies in order to remove eventual residual layers normally responsible for irregularities in the micromachine etching task. It is realized by dipping them in $\mathrm{HCl}: \mathrm{H}_{2} \mathrm{O}(1: 10)-20 \mathrm{~s}$, then rinsing in deionized water $-10 \mathrm{~s}$, dipping in $\mathrm{NH}_{4} \mathrm{OH}: \mathrm{H}_{2} \mathrm{O}(1: 1)-20 \mathrm{~s}$, and, finally, drying with nitrogen. The dies are then dipped in the etching solution, according to the specific parameters of concentration, temperature, and stirring. Selective and preferential etching characteristics are not taken into account since no GaAs material is kept underneath the structure. Therefore, a great number of GaAs etchants, such as $\mathrm{C}_{6} \mathrm{H}_{8} \mathrm{O}_{7}: \mathrm{H}_{2} \mathrm{O}_{2}$ (citric acid)-, $\mathrm{H}_{3} \mathrm{PO}_{4^{-}}, \mathrm{H}_{2} \mathrm{SO}_{4^{-}}$, and $\mathrm{NH}_{4} \mathrm{OH}$-based solutions are suitable [17].

\section{THEORETICAL ANALYSIS AND LUMPED MODELS}

\section{A. Freestanding Microstrip}

The equivalent lumped model of a microstrip transmission line, which represents a small subsection per unit length, is shown in Fig. 2(a). The circuit parameters $R, L, C$, and $G$ are deduced at each frequency point from the propagation constant and characteristic impedance by using the classical Telegrapher's transmission - line equation [18]. The conductance $G$ is usually neglected when a semiinsulating GaAs substrate is used. The series resistance $R$, on the other hand, is governed by the skin effect and can be computed using Pettenpaul's equation [19]

$$
\begin{aligned}
R=\frac{l}{w t \sigma}\left[\frac{0.431 x_{w}}{1+0.041(w / t)^{1.19}}\right. & +\frac{1.1147+1.2868 x_{w}}{1.2296+1.287 x_{w}^{3}} \\
& \left.+0.0035\left(\frac{w}{t}-1\right)^{1.8}\right]
\end{aligned}
$$

for $x_{w}>=2.5$ and

$$
R=\frac{l}{w t \sigma}\left[1+0.0122 x_{w}^{\left(3+0.01 x_{w}^{2}\right)}\right]
$$

for $x_{w}<2.5$ and with $x_{w}=(2 \partial \sigma \mu w t)^{1 / 2}$ a normalized frequency, where $\sigma$ represents the conductivity, $\mu$ is the permeability, $w$ is the width, and $t$ is the thickness of the metallic conductor with rectangular cross section.

Inductance $L$, per unit length, can be estimated by using the Grover formulation [20] and taking into account the groundplane effects since the substrate thickness $(h)$ is low when compared to the microstrip length $(l)$ [21]

$$
L=\frac{\mu_{o} l}{2 \pi}\left[\ln \left(\frac{2 h}{w+t}\right)+\frac{w+t}{3 l}-\frac{2 h}{l}+1.5\right] .
$$

In fact, the capacitance $C$ represents the most important parameter in this paper because it is directly affected by micromachining. A computer program based on a two-dimensional method of moments (MOM) has been used to evaluate the effective permittivity $\left(\varepsilon_{\text {reff }}\right)$ of the microstrip line as a function of the air layer thickness. This analysis showed that it is not necessary to obtain high air-gap height because the $\varepsilon_{r \text { eff }}$ decreases exponentially with the etching depth, as shown in Fig. 3. As a result, the capacitance between the wires and the backside ground

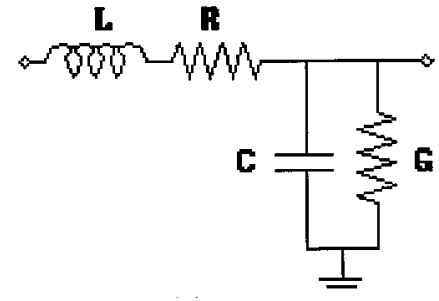

(a)

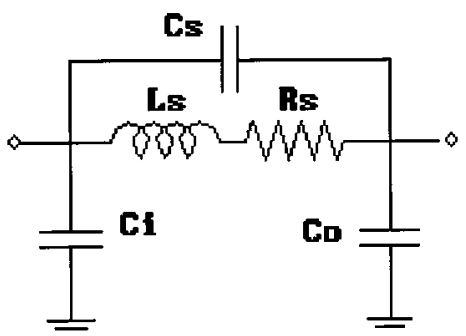

(b)

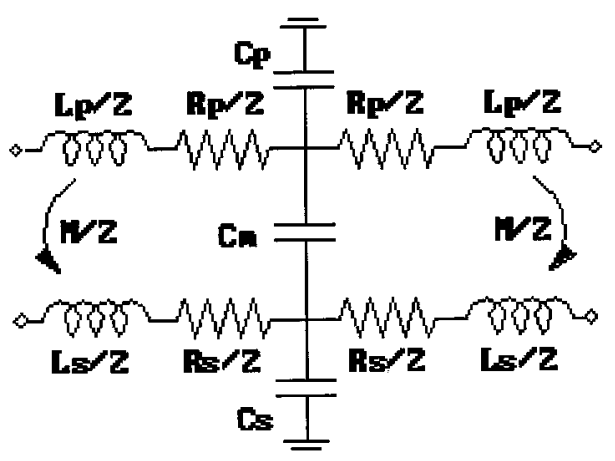

(c)

Fig. 2. Lumped-element equivalent models. (a) Microstrip line. (b) Planar inductor. (c) Transformer.

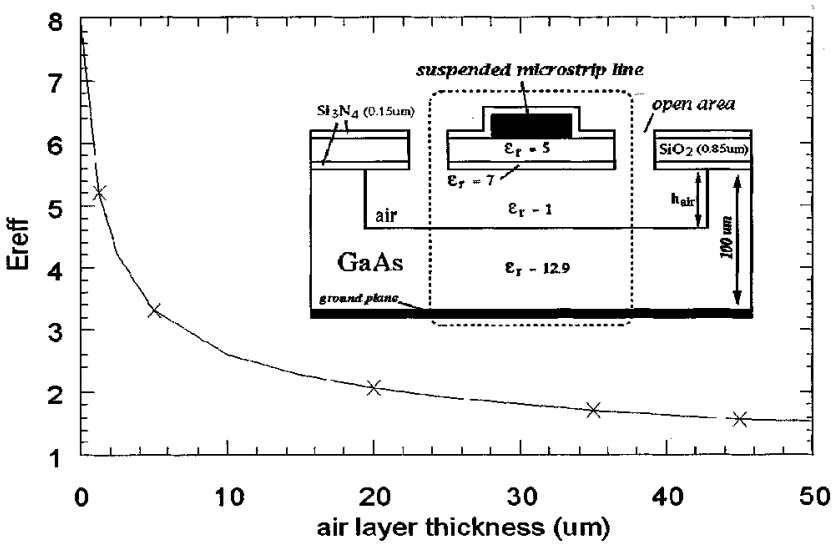

Fig. 3. Effective permittivity versus air-gap height of a suspended microstrip line.

plane is expected to reduce, e.g., twice by removing just 5\% of the bulk material underneath the metal line.

\section{B. Planar Spiral Inductor}

The planar spiral inductor structure is known to be more compact and space efficient than the equivalent straight wire con- 


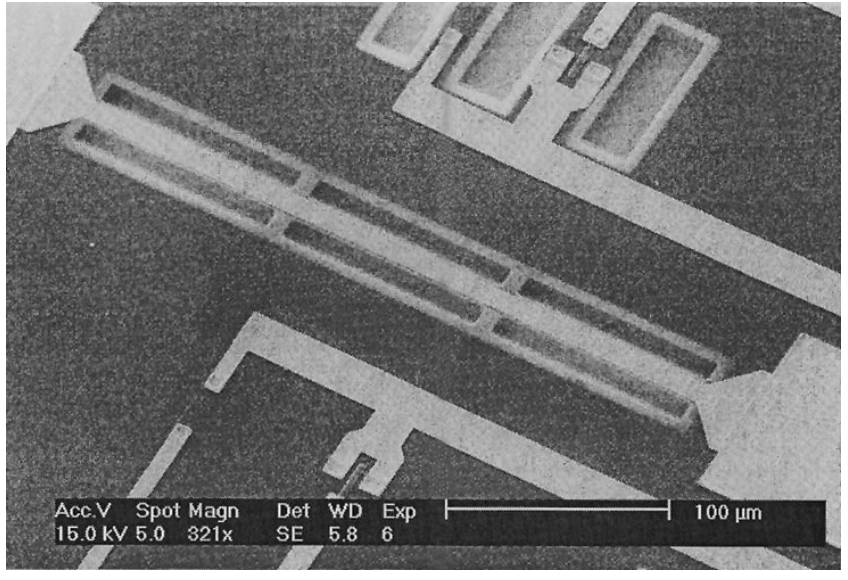

Fig. 4. Microphotograph of 0.5-mm-long suspended microstrip line.

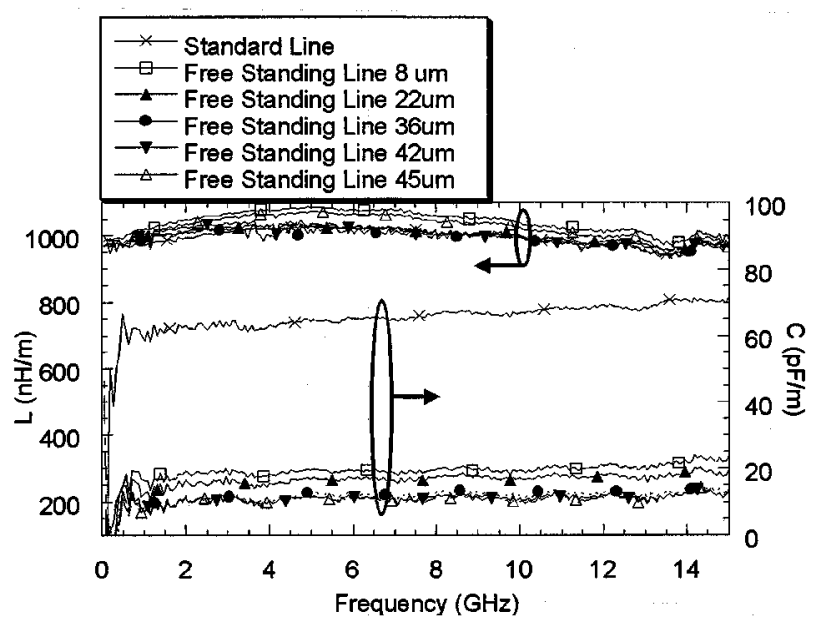

(a)

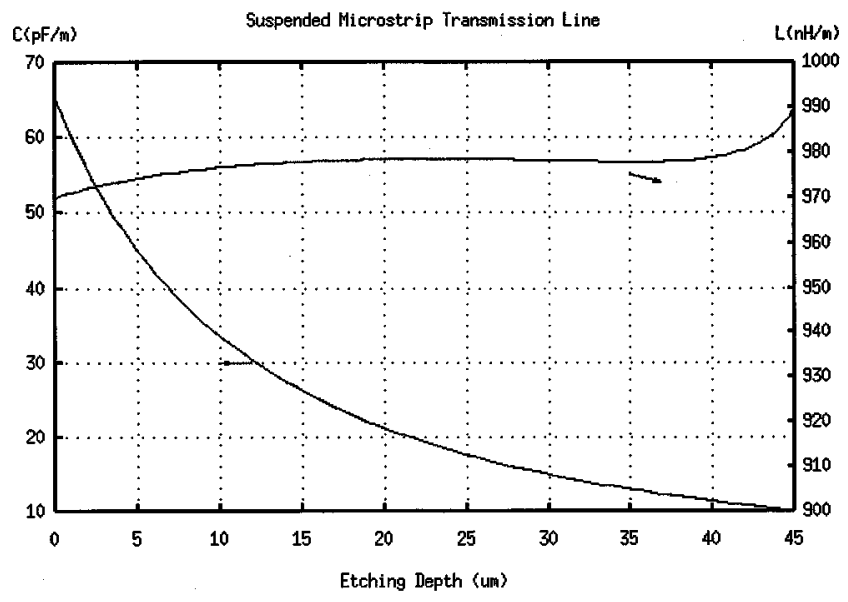

(b)

Fig. 5. Inductance and capacitance, per unit length, of $5 \mu \mathrm{m}$-wide and $2 \mathrm{~mm}$-long microstrip versus (a) frequency and (b) air-gap height-etching depth.

ductor. In the corresponding lumped-element equivalent circuit, illustrated in Fig. 2(b), the series branch is formed by the spiral

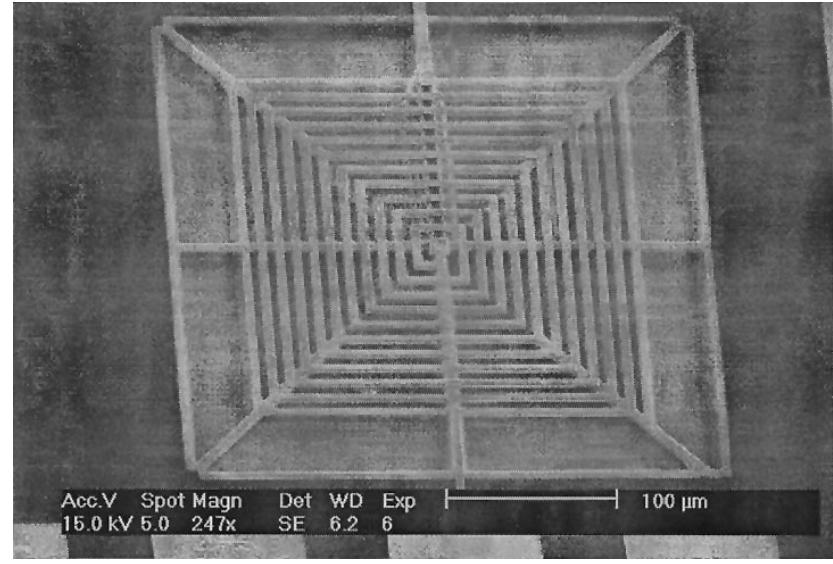

Fig. 6. Microphotograph of 12-nH planar spiral inductor with isolated strips.

inductance $L_{s}$, fringing capacitance $C_{s}$, and wire series resistance $R_{s}$. At first, $L_{s}$ can be estimated using the equations proposed by Greenhouse [22]

$$
L_{s}=\sum_{i=1}^{N} L_{i}+\sum_{i=1}^{N} \sum_{j=1}^{N} M_{i j}
$$

where $L_{i}$ represents the self-inductance of each straight segment $i$, and $M_{i j}$ is the mutual inductance between the parallel segments $i$ and $j$. The $M_{i j}$ value is a function of the strips length $(l)$ and the distance between the track centers $(d)$, and can be calculated through the following equation:

$$
M_{i j}=\frac{\mu_{o} l}{2 \pi}\left\{\ln \left[\frac{l}{D}+\sqrt{1+\left(\frac{l}{D}\right)^{2}}\right]-\sqrt{1+\left(\frac{D}{l}\right)^{2}}+\frac{D}{l}\right\}
$$

where

$$
\ln (D)=\ln (d)-\left[\frac{1}{12}\left(\frac{w}{d}\right)^{2}+\frac{1}{60}\left(\frac{w}{d}\right)^{4}+\frac{1}{168}\left(\frac{w}{d}\right)^{6}+\cdots\right]
$$

Notice that $M_{i j}$ is positive when the currents in two parallel conductors are in the same direction, and negative when they are in the opposite directions. This approach assumes that perpendicular segments present negligible mutual inductances. A more general form of (4) can be derived to calculate the mutual inductance of filamentary conductors with arbitrary lengths and without coincident ends [20]. Moreover, in order to consider the backside ground plane, an additional procedure includes the mutual inductance caused by a fictional mirror image, which is located at a distance of twice the substrate thickness from the actual spiral. The reduction in inductance value, in this case, is accounted for by the reverse current flow in the image spiral.

On the other hand, $R_{s}$ is derived from (1a) and (1b) by considering the total length of the spiral inductor, while the series capacitance $C_{s}$ accounts for the fringing capacitance between the spiral wires and between these wires and the center-tap underpass. The parasitics in the shunt branches are modeled by $C_{i}$ 
TABLE I

Characteristics OF STANDARD AND Micromachined Planar INDUCTOR WITH IsOlated StRIPS

\begin{tabular}{|c|c|c|c|c|c|c|c|c|}
\hline $\begin{array}{l}\text { Air gap height } \\
\text { (etching depth) }\end{array}$ & $\begin{array}{r}\mathrm{R}_{\mathrm{S}} \\
()\end{array}$ & $\begin{array}{l}\mathrm{L}_{\mathrm{S}} \\
(\mathrm{nH})\end{array}$ & $\begin{array}{l}\mathrm{C}_{\mathrm{O}} \\
\text { (fF) }\end{array}$ & $\begin{array}{l}\mathrm{C}_{\mathrm{i}} \\
(\mathrm{fF})\end{array}$ & $\begin{array}{l}\mathrm{C}_{\mathrm{S}} \\
(\mathrm{fF})\end{array}$ & $\begin{array}{c}f_{\text {res }} \\
(\mathrm{GHz})\end{array}$ & $\begin{array}{l}f_{\mathrm{Qmax}} \\
(\mathrm{GHz})\end{array}$ & $\mathrm{Q}_{\max }$ \\
\hline standard & 10.5 & 4.8 & 50 & 42 & 6 & 10.5 & 6.1 & 11.5 \\
\hline $10 \mu \mathrm{m}$ & 10.5 & 4.8 & 30 & 25 & 5 & 13.3 & 7.7 & 14.6 \\
\hline $40 \mu \mathrm{m}$ & 10.5 & 4.8 & 12 & 10 & 6 & 17.1 & 9.9 & 18.9 \\
\hline standard & 30 & 12 & 65 & 50 & 10 & 5.3 & 3.1 & 5.1 \\
\hline $8 \mu \mathrm{m}$ & 28 & 12 & 50 & 45 & 6 & 6.2 & 3.6 & 6.3 \\
\hline $22 \mu \mathrm{m}$ & 29 & 12 & 31 & 29 & 6 & 7.6 & 4.4 & 7.5 \\
\hline $42 \mu \mathrm{m}$ & 29 & 12 & 6 & 3 & 6 & 13.4 & 7.7 & 13.3 \\
\hline
\end{tabular}

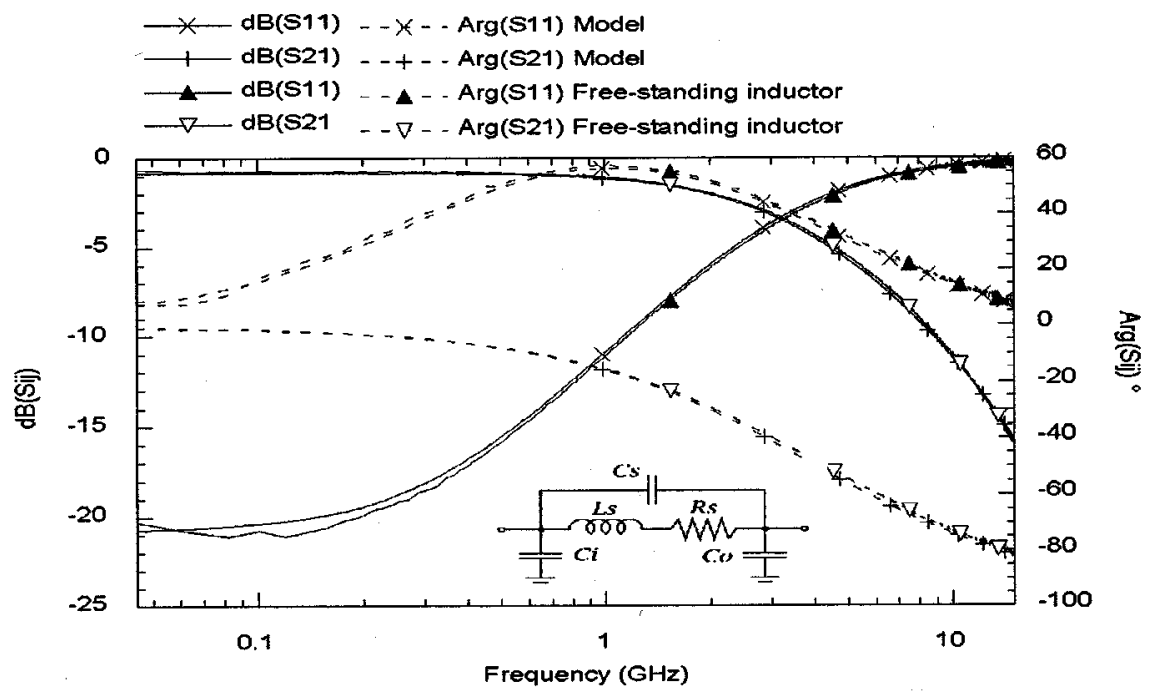

Fig. 7. $S$-parameter measurements versus inductor lumped model.

and $C_{o}$, which represent the substrate capacitances between the strips and ground plane, and can be computed with the two-dimensional (2-D) MOM technique, mentioned above, by considering a multiconductor structure.

The $Q$ factor of the planar inductor, defined as the ratio of the imaginary part to the real part of the one-port input impedance with the other side grounded, can be calculated by using the following expression:

$$
Q=\frac{\omega L_{s}}{R_{s}}\left[1-\frac{R_{s}^{2}\left(C_{s}+C_{o}\right)}{L_{s}}-\omega^{2} L_{s}\left(C_{s}+C_{o}\right)\right]
$$

where the term in brackets represents the self-resonant factor which describes the reduction of the $Q$ factor caused by parasitic capacitance effects. To illustrate the predicted improvements resulted from micromachining, a 15-nH inductor with $10-\mu \mathrm{m}$-wide and $5-\mu \mathrm{m}$-spacing segments was taken as a case of study, using the model element values provided by PML, i.e., $R_{s}=23.4, C_{s}=2.2 \mathrm{fF}$, and $C_{i}=200 \mathrm{fF}$. Considering that $C_{i}$ and $C_{s}$ reduce three times, the maximum $Q$ factor is expected to increase from 4.5 (at $1.6 \mathrm{GHz}$ ) to around 7.8 (at $2.9 \mathrm{GHz}$ ), and the resonant frequency may be shifted from 2.8 to $5.1 \mathrm{GHz}$.

\section{Planar Spiral Transformer}

The spiral transformer structure, investigated herein, consists of two identical spiral inductors interwound. The lumped-element model proposed by Frlan et al. [14], and illustrated in Fig. 2(c), was adopted herein. $R_{1}$ and $R_{2}$ are the series resistance, while $L_{1}$ and $L_{2}$ are the total inductances of the primary and secondary, respectively, and, since the structure is formed by identical spiral inductors, these values are identical. $M$ represents the mutual inductance between the coils.

Once again, the static self-inductance and mutual inductance between parallel segments are calculated according to the method described for planar inductors, always considering the ground-plane effects as well as the estimation of the segment-to-ground and the mutual interline capacitances. The capacitance between nonadjacent lines are neglected with no significant change in the final accuracy of the model, unlike the total inductance in which all the individual self-inductances must be accounted for.

\section{RESULTS AND DISCUSSION}

Prototypes containing test structures were fabricated using the commercial PML D02AH process through the circuit mul- 


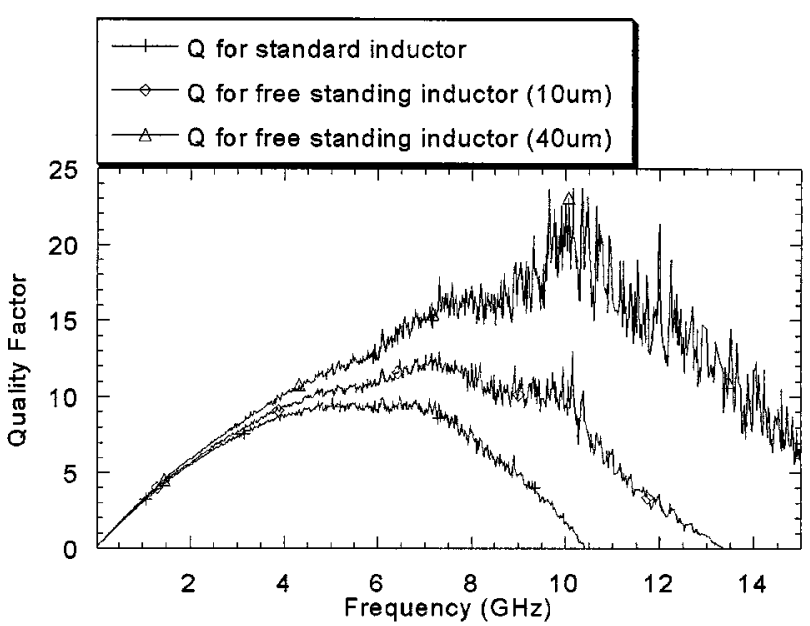

(a)

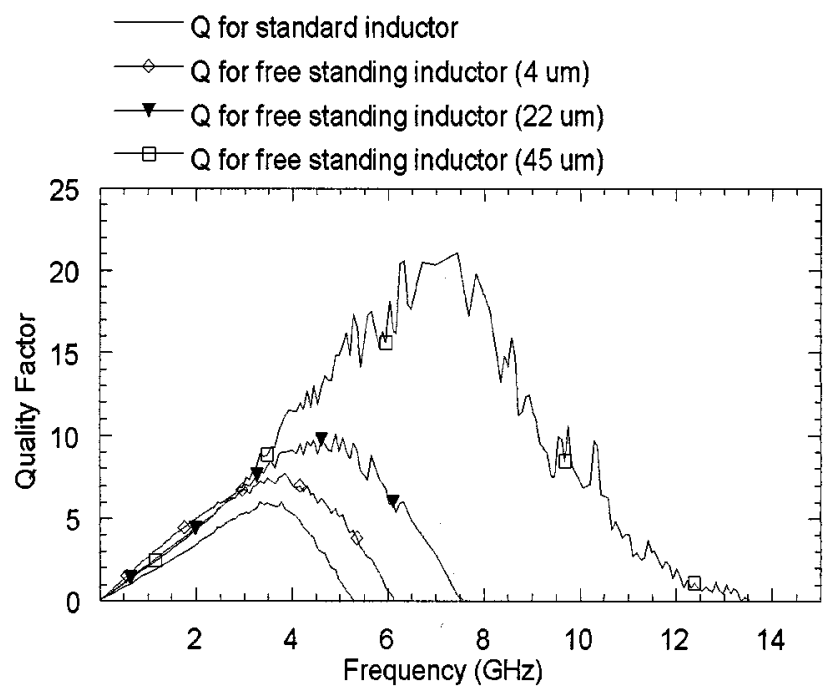

(b)

Fig. 8. $\quad Q$ factor versus air-gap height of (a) 4.9- and (b) 12-nH inductors.

tiproject (CMP) wafer service [23]. The dies were then exposed one by one to the post-fabrication wet etching, considering a wide range of etching time in order to obtain freestanding structures with different air-gap heights. Two-port $S$-parameter measurements were performed for the frequency range from 0.5 to $15 \mathrm{GHz}$, using the HP8510B network analyzer and a Cascade Microtech probe station. Open, short, thru, and 50 structures were available on a standard substrate for short open load thru (SOLT) calibration. Moreover, open-circuit test patterns were probed to measure pad parasitics for deembedding. The measured data were transmitted to a computer for automatic parameter extraction. Prior to each acquisition, an additional procedure based on the $Y$-parameter subtraction method was used to remove the parasitic effects from the probe pads [24].

\section{A. Freestanding Microstrip}

Suspended microstrip lines were constructed to evaluate the influence of micromachining in the $L$ and $C$ lumped model parameters (see Fig. 4). Dielectric arms, with 5- $\mu$ m width and $10-\mu \mathrm{m}$ length, were placed at each $100 \mu \mathrm{m}$ along the long lines

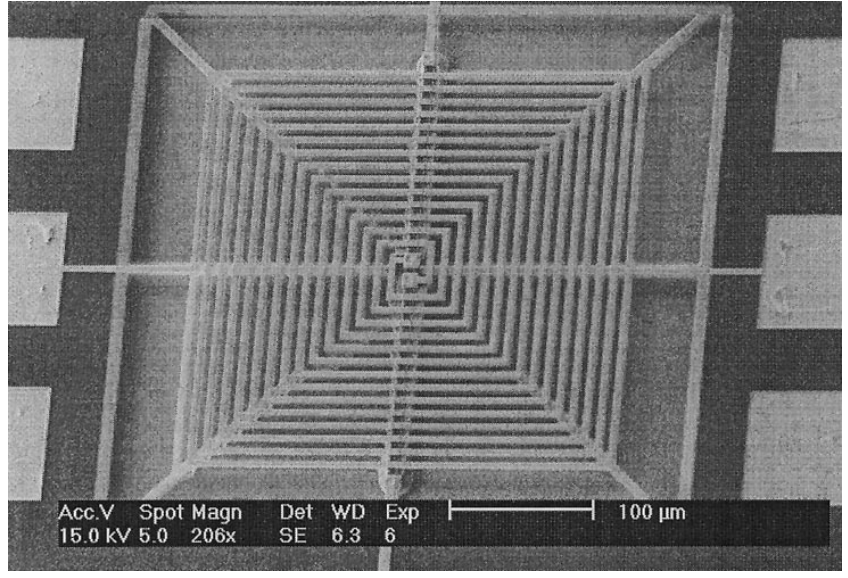

Fig. 9. Microphotograph of micromachined planar spiral transformer.

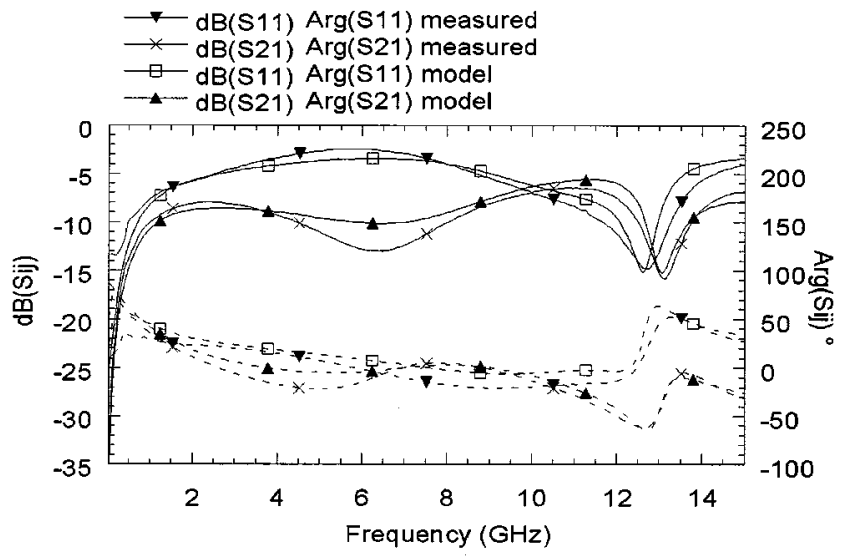

(a)

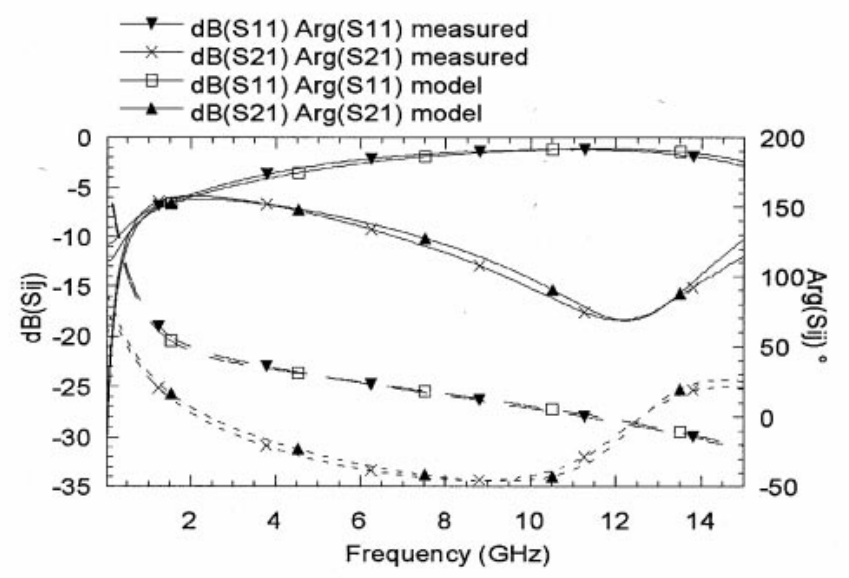

(b)

Fig. 10. $S$-parameter measurements versus lumped-element model of: (a) standard and (b) $42-\mu \mathrm{m}$-depth suspended planar spiral transformer.

for mechanical support. Measurements have shown that both $L$ and $C$ are relatively frequency independent, as illustrated in Fig. 5(a). Moreover, in respect to the etching depth, $C$ exhibited an exponential decreasing with the air layer thickness, agreeing as well with the computed effective permittivity discussed above [see Fig. 5(b)]. On the other hand, $L$ is not really affected by micromachining because it is predominantly determined by the magnetic flux external to the conductor. 


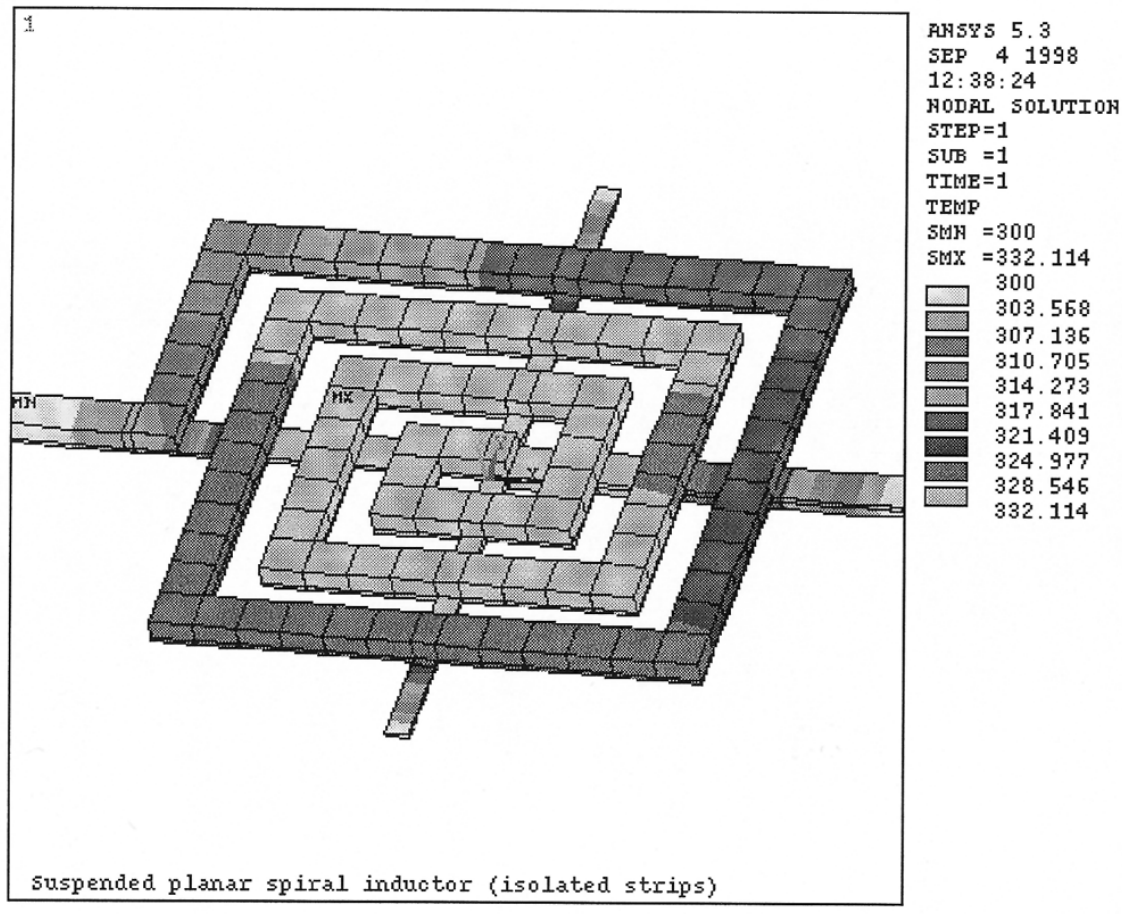

Fig. 11. FEM solid model: temperature distribution on micromachined planar inductors with isolated strips.

\section{B. Planar Spiral Inductor}

Two planar spiral inductors were fabricated and post-process etched: a 4.9- and a 12-nH inductors composed by five and seven turns, respectively. Both inductors are formed by $5-\mu \mathrm{m}$-wide and 5- $\mu \mathrm{m}$-spacing segments. In the case of the 12-nH inductor structure, the three most external spiral turns are supported by thin dielectric arms at four corners to prevent eventual mechanical fracture, as shown in Fig. 6.

The measured inductance, obtained from $Y$-parameters $L_{s}=$ $\operatorname{Im}\left(1 / y_{12}\right) / \omega$ agrees well with the predicted theoretical values at low frequencies. Notice that the negative mutual inductance due to image spiral equal to 0.3 and $3.7 \mathrm{nH}$ for the 4.9 - and 12-nH inductors, respectively, was verified to be an important parameter in the lumped-element modeling. Moreover, the measured resistive component $R_{s}=\operatorname{Re}\left(1 / y_{12}\right)$ is closed to the dc resistance of the spiral line.

On the other hand, the extracted capacitances were obtained directly from $C_{i}=\operatorname{Im}\left(y_{11}+y_{12}\right) / \omega$ and $C_{o}=\operatorname{Im}\left(y_{22}+\right.$ $\left.y_{21}\right) / \omega$, and are summarized in Table I. As expected, a significant reduction was verified with the suspended structures. However, the $C_{s}$ value was found to be predominantly determined by the spiral and center-tap underpass capacitance, not influenced by micromachining. As a result, the decreasing of fringing capacitances becomes more evident by increasing the number of spiral turns, as occurred in the 12-nH inductor.

The equivalent-element model behavior agrees well with the measured $S$-parameters, as illustrated in Fig. 7. As shown in Fig. 8, the $Q$ factor, the frequency at the maximum $Q$, and the resonant frequency were significantly improved by micromachining. These characteristics are listed in Table I and were ob- tained considering the average values of the element model parameters, also presented in this table.

\section{Planar Spiral Transformer}

The fabricated micromachined transformer is composed by two interleaved seven-turn spiral inductors, presenting 6- $\mu \mathrm{m}$-wide and $6-\mu \mathrm{m}$-spacing segments, as shown in Fig. 9. The extracted element values are $L_{p}=L_{s}=8.6 \mathrm{nH}$, $M=6.8 \mathrm{nH}$, and $R_{p}=R_{s}=30$. Since the lowering in self inductance due to its own image spiral is $0.85 \mathrm{nH}$ and the mutual inductance between one actual spiral and the image of the other is $0.8 \mathrm{nH}$, it is imperative to take into account the ground-plane effects on self and mutual inductances for the lumped model accuracy. The extracted capacitances were obtained equal to $C_{p}=C_{s}=40 \mathrm{fF}$ and $C_{m}=200 \mathrm{fF}$ for the standard transformer, they reduced to $C_{p}=C_{s}=15 \mathrm{fF}$ and $C_{m}=80 \mathrm{fF}$ in the micromachined structure, with an air-gap underneath the strips equals to $42 \mu \mathrm{m}$. The comparison between measured and simulated $S$-parameters of standard and suspended transformers is shown in Fig. 10.

\section{HEATING AND MeChaniCAL CHARACTERISTICS}

Besides electrical performance, thermal and mechanical characteristics are also very important to verify the usefulness of these micromachined devices. It is well known that freestanding structures have been widely used in thermo-electrical-based micromachined devices, such as bolometers and thermopiles, since suspended parts present poor heat dissipation acting as "hot regions" either for temperature sensing 


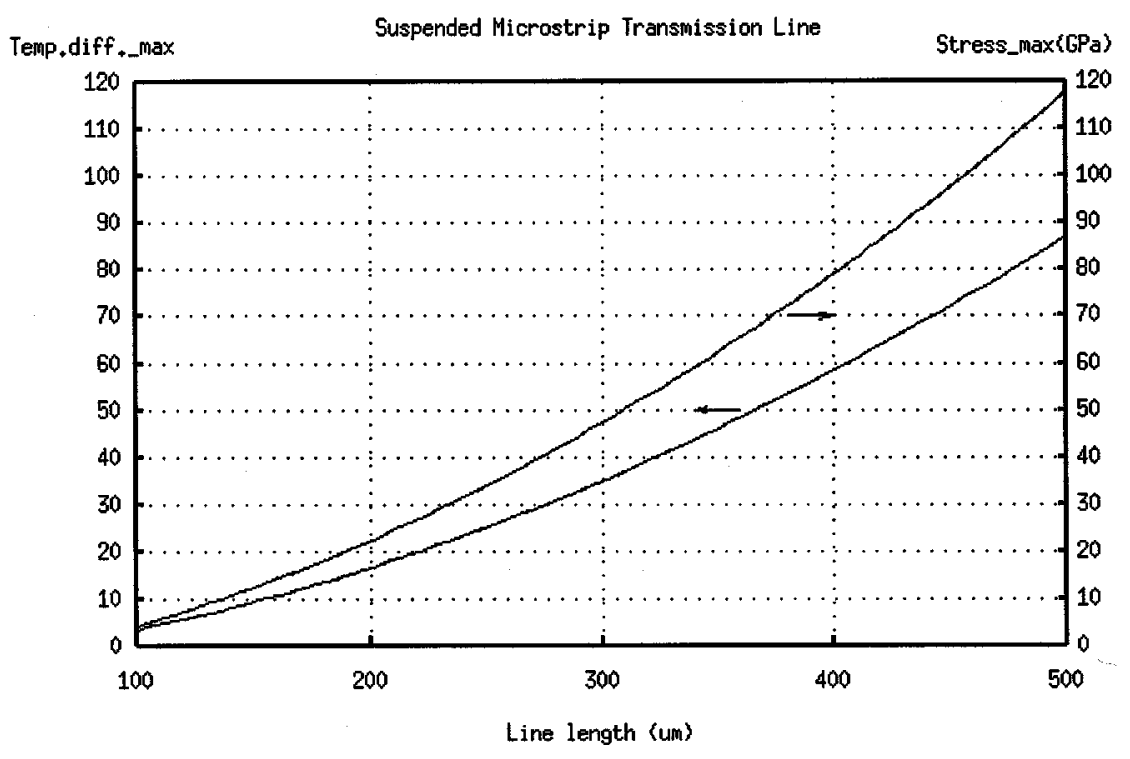

(a)

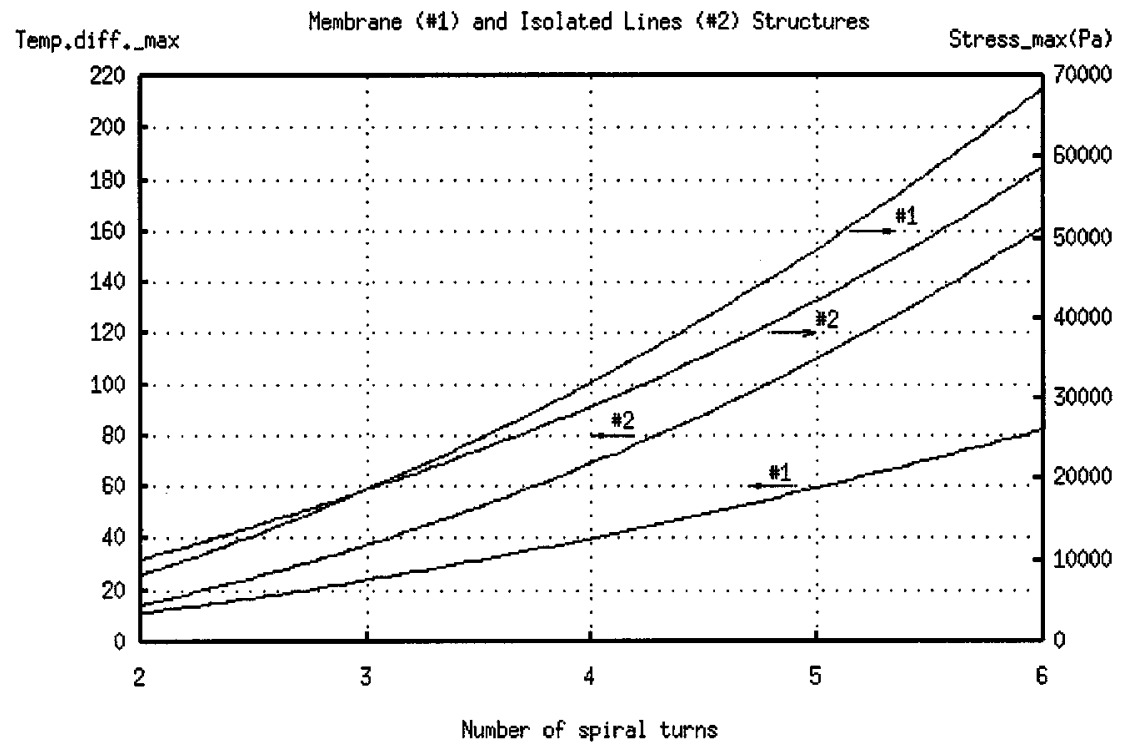

(b)

Fig. 12. Maximum temperature difference and mechanical stress of micromachined structures. (a) Microstrip line. (b) Planar spiral inductors over membrane and with isolated lines.

or to Seebeck voltage generation, considering the substrate as heat sink ("cold region"). However, in the case of suspended microwave passive devices, it represents a constraint due to the increasing series resistance of the wires. On the other hand, the mechanical constraints are essential to prove the structure applicability. A complete analysis of such characteristics was carried out through extensive finite-element method (FEM) simulations, as illustrated in Fig. 11.

\section{A. Heat Distribution}

The maximum temperature difference of a single and straight suspended microstrip line as a function of the bridge length was obtained from FEM simulations using the worst-case current value, i.e., the maximum current determined by PML for the interconnection metal [see Fig. 12(a)]. Such behavior was observed almost invariant in terms of the linewidth. Moreover, both versions of planar spiral inductors, over a membrane and with isolated strips, were also investigated for the maximum current allowed. The maximum increasing temperature as a function of the number of spiral turns is shown in Fig. 12(b). Note that the heat dissipation is slightly better for the membrane structure. Furthermore, since the typical value of the temperature coefficient of resistivity (TCR) for metals is 
usually $5 \times 10^{-3} \mathrm{~K}$, an increasing of $100^{\circ}$ may result in $50 \%$ increasing of line series resistance, which directly influence the inductor $Q$ factor.

\section{B. Mechanical Stress}

In the mechanical evaluation, an acceleration of $100 \mathrm{~g}$ (i.e., $980 \mathrm{~m} / \mathrm{s}^{2}$ ) was used in FEM simulations. To have an idea about such acceleration value, air-bag accelerometers for automotive systems work at range of $\pm 50 \mathrm{~g}$ [25]. Similarly to temperature behavior, the maximum stress as well as the maximum displacement were also observed approximately invariant in respect to the microstrip width. In the case of suspended planar inductors, the maximum stress was obviously observed in the most external dielectric arms, and it is shown in Fig. 12(b) as a function of the number of spiral turns. Note that $\mathrm{SiO}_{2}$ presents the lowest fracture strength (50-55 MPa) among the structure layers. In other words, according to simulation results, this suspended inductor can be considered mechanically very robust. Nevertheless, it is suggested to use dielectric arms at four corners for larger spiral structures. Finally, the internal stress between the IC layers could be very critical, but it cannot be evaluated through such a type of simulation. A more detailed study about mechanical properties of micromachined devices is out of the scope of this paper.

\section{CONClusions}

The front-side bulk micromachining compatible to a standard GaAs HEMT technology has been demonstrated to be very useful for performance improvement of microwave passive devices, in particular, inductors and transformers. Such straightforward and cost-effective micromachining technique allowed the creation of a new and promising planar spiral inductor structure with the strips suspended separately, significantly reducing shunt and fringing capacitances. The self-resonant frequency and maximum $Q$ factor of micromachined compounds have increased up to $250 \%$. Moreover, mechanical constraints were verified as being not so critical, while careful attention must paid to heat dissipation depending on the electrical current used. Furthermore, the fact that the D02AH process from PML, considered in this paper, is available to MMIC design, filters, matching networks, and low-noise amplifiers, and other RF circuits can be directly enhanced by using such approach.

\section{ACKNOWLEDGMENT}

The authors would like to thank J. Haidar, Laboratoire d'Electromagnétisme Microondes et Optoélectroniques (LEMO), Ecole Nationale Superieure d'Electronique et de Radioelectricite de Grenoble (ENSERG), Grenoble, France, for his helpful assistance in these measurements.

\section{REFERENCES}

[1] L. M. Burns, "Integrated circuit technology options for RFIC's-present status and future directions," IEEE J. Solid-State Circuits, vol. 33, pp. 387-399, Mar. 1998.

[2] J. N. Burghartz, M. Soyuer, and K. A. Jenkins, "Microwave inductors and capacitors in standard multilevel interconnect silicon technology," IEEE Trans. Microwave Theory Tech., vol. 44, pp. 100-104, Jan. 1996.

[3] A. C. Reyes, S. M. El-Ghazaly, S. J. Dorn, M. Dydyk, D. K. Schroder, and H. Patterson, "Coplanar waveguides and microwave inductors on silicon substrates," IEEE Trans. Microwave Theory Tech., vol. 43, pp. 2016-2022, Sept. 1995.

[4] K. B. Ashby, I. A. Koullias, W. C. Finley, J. J. Bastek, and S. Moinian, "High $Q$ inductors for wireless applications in a complementary silicon bipolar process," IEEE J. Solid-State Circuits, vol. 31, pp. 4-9, Jan. 1996.

[5] M. Park, S. Lee, H. K. Yu, J. G. Koo, and K. S. Nam, "High $Q$ CMOScompatible microwave inductors using double-metal interconnection silicon technology," IEEE Microwave Guided Wave Lett., vol. 7, pp. 45-47, Feb. 1997.

[6] J. N. Burghartz, D. C. Edelstein, K. A. Jenkins, and Y. H. Kwark, "Spiral inductor and transmission lines in silicon technology using copper-damascene interconnects and low-loss substrates," IEEE Trans. Microwave Theory Tech., vol. 45, pp. 1961-1968, Oct. 1997.

[7] C.-Y. Chi, and G. M. Rebeiz, "Planar microwave and millimeter-wave lumped elements and coupled-line filters using micro-machining techniques," IEEE Trans. Microwave Theory Tech., vol. 43, pp. 730-738, Apr. 1995.

[8] T. M. Weller, K. J. Herrick, and L. P. B. Katehi, "Quasi-static design technique for mm-wave micromachined filters with lumped elements and series stubs," IEEE Trans. Microwave Theory Tech., vol. 45, pp. 931-938, June 1997.

[9] J. Y.-C. Chang, A. A. Abidi, and M. Gaitan, "Large suspended inductors on silicon and their use in a $2-\mu \mathrm{m}$ CMOS RF amplifier," IEEE Electron Device Lett., vol. 14, pp. 246-248, May 1993.

[10] V. Milanovic, M. Gaitan, E. D. Bowen, and M. E. Zaghloul, "Micromachined microwave transmission lines in CMOS technology," IEEE Trans. Microwave Theory Tech., vol. 45, pp. 630-635, May 1997.

[11] J. M. López-Villegas, J. Samitier, J. Bausells, A. Merlos, C. Cané, and R. Knöchel, "Study of integrated RF passive components performed using CMOS and Si micromachining technologies," J. Micromech. Microeng., vol. 7, pp. 162-164, 1997.

[12] S. M. Sze, Semiconductor Sensors. New York: Wiley, 1994.

[13] R. P. Ribas, N. Bennouri, J. M. Karam, and B. Courtois, "GaAs MEMS design using $0.2 \mu \mathrm{m}$ HEMT MMIC technology," in IEEE GaAs IC Tech. Symp. Dig., Oct. 1997, pp. 127-130.

[14] E. Frlan, S. Meszaros, M. Cuhaci, and J. S. Wight, "Computer aided design of square spiral transformers and inductors," in IEEE MTT-S Int. Microwave Symp. Dig., Long Beach, CA, June 1989, pp. 661-664.

[15] G. G. Rabjohn, "Monolithic microwave transformers," M. Eng. thesis, Carleton Univ., Ottawa, Ont., Canada, 1991.

[16] "D02AH Design Manual," Philips Microwave, Limeil, France, Doc. PML-G-SC-0008-E / V2.0, Jan. 1997.

[17] R. P. Ribas, J. L. Leclercq, J. M. Karam, B. Courtois, and P. Viktorovitch, "Bulk micromachining characterization of $0.2 \mu \mathrm{m}$ HEMT MMIC technology for GaAs MEMS design," Mater. Sci. Eng., no. 1-3, pp. 267-273, Feb. 1998.

[18] W. R. Eisenstadt and Y. Eo, " $S$-parameter-based IC interconnect transmission line characterization," IEEE Trans. Comp., Hybrids, Manufact. Technol., vol. 15, no. 4, Aug. 1992.

[19] E. Pettenpaul, H. Kaputsa, A. Weisgerber, H. Mampe, J. Luginsland, and I. Wolff, "CAD models of lumped elements on GaAs up to $18 \mathrm{GHz}$," IEEE Trans. Microwave Theory Tech., vol. 36, pp. 294-304, Feb. 1988.

[20] F. W. Grover, Inductance Calculations. New York: Van Nostrand, 1946.

[21] D. Krafesik and D. Dawson, "A closed-form expression for representing the distributed nature of the spiral inductor," in IEEE MTT-S Monolithic Circuits Symp. Dig., Baltimore, MD, 1986, pp. 87-91.

[22] H. M. Greenhouse, "Design of planar rectangular microelectronic inductors," IEEE Trans. Parts, Mater, Packag., vol. PMP-10, pp. 101-109, June 1974. 
[23] B. Courtois, "Access to microsystem technology: The MPC services solution," Microelectron. J., vol. 28, no. 4, pp. 407-417, May 1997.

[24] P. J. Van Wijnen, H. R. Claessen, and E. A. Wolshereimer, "A new straight forward calibration and correction procedure for on-wafer high frequency $S$-parameter measurements $(45 \mathrm{MHz}-18 \mathrm{GHz})$," in BCTM Dig., 1987, pp. 70-73.

[25] C. Song, "Commercial vision of siliconed inertial sensors," in Proc. Int. Solid-State Sens. Actuators-Transducers' 97 Conf., Chicago, IL, pp. 839-842.

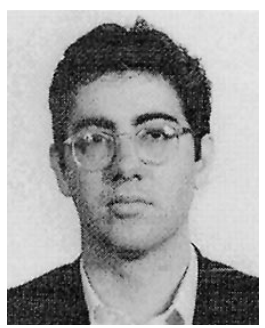

Renato P. Ribas was born in Santa Rosa, Brazil, in 1969. He received the B.S. degree in electrical engineering from the Universidade Federal do Rio Grande do Sul (UFRGS), Rio Grande do Sul, Brazil, in 1991, the M. S. degree from the Universidade de Campinas (Unicamp), Brazil, in 1994, respectively, both in electrical engineering, and the Dr.Eng. degree in microelectronics from the Institut National Polytechnique de Grenoble (INPG), Grenoble, France, in 1998.

From 1991 to 1994, he was with the Integrate Circuit Design Laboratory (LPCI-IM), Fundação Centro Tecnológico para Informática (CTI), Campinas, Brazil. In 1999, he was a Visiting Researcher at the Instituto de Informática, Pontificia Universidade Catolica (PUC) Campinas, Brazil. In 2000, he became an Assistant Professor at the Instituto de Informática, UFRGS. His major research interest lies in RF MEMS devices and micromachined device modeling and computer-aided design (CAD) tools.

Dr. Ribas has been a member of the Brazilian Microelectronics Society (SBMicro) Council since 1999

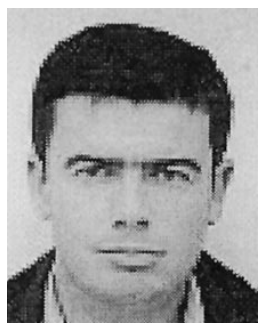

Jérome Lescot was born in Lyon, France, in 1973. $\mathrm{He}$ received the Engineering degree in electronics and the Advanced Research degree in optics and microwaves from the Ecole Nationale Superieure d'Electronique et de Radioelectricite de Grenoble (ENSERG), Grenoble, France, in 1996, and the Ph.D. degree (with highest honors) in optics and microwaves from the Polytechnic Institute of Grenoble (INPG), Grenoble, France, in 2000.

$\mathrm{He}$ is currently an Application Engineer at Simplex, Sunnyvale, CA, where he is involved in the modeling of substrate crosstalk in digital and mixed-signal circuits on silicon. From 1996 to 1999, he developed a numerical method dedicated to the modeling of integrated passive components on heavily doped Si substrates for wireless applications. His current research interests include numerical methods in electromagnetic and RF CAD.

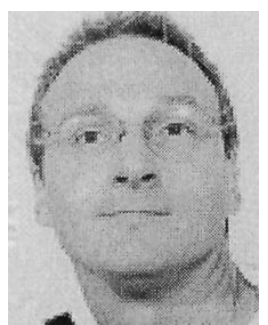

Jean-Louis Leclercq was born in 1964. He received the Ph.D. degree in chimie des matériaux from the University of Montpellier II, Montpellier, France, in 1990. His dissertation focused on PECVD processing for InP-based MISFET's.

In 1990, he joined the French CNRS as a permanent Reasearcher in 1990. From 1990 to 1992, he was with EM2, University of Montpellier II, where he developed GaSb-based laser diodes. In 1992, he joined the Laboratoire d'Electronique, Optoelectronique et Microsystemes (LEOM), Ecole Centrale de Lyon, Ecully, France, where he currently manages III-V-based microtechnologies and microsystems developments. His current interests include optoelectronics, micromachining, and microfabrication related to III-V-based materials for photonic systems. He has authored or co-authored approximately 25 papers in international journals and 30 international conferences.

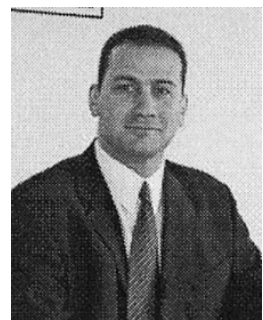

Jean Michel Karam (M'99) received the Ph.D. degree in microelectronics (with highest honors) from the Institut National Polytechnique de Grenoble, Grenoble, France, in 1996, the Advanced Studies degree in microelectronics from the University of Paris VII, Paris, France, the Engineering degree from the Ecole Supérieure d'Ingénieurs en Electrotechnique et Electronique, Paris, France, in 1993, and the degrees in superior and special mathematics from the Ecole Supérieure d'Ingénieurs de Beyrouth, Beyrouth, France, in 1987 and 1989, respectively.

In 1994, he joined the Techniques de l'Informatique de la Microelectronique pour l'Architecture d'ordinateurs Laboratory (TIMA) Laboratory, Grenoble, France, where, in 1995, he began the Microsystems Group that focused on MEMS development, and then built the group up to over 25 engineers by establishing close ties with major European and U.S. companies. He additionally launched and managed the MEMS manufacturing programs of service. $\mathrm{He}$ has also consulted for many companies in both technical and marketing issues, including clients such as Mentor Graphics, where he contributed to the marketing efforts for the company's analog/mixed signal (A/MS) and MEMS business beginning in 1996. In 1997, he founded MEMSCAP, which is the leading provider of commercial design technology for the development of MEMS, and became its President and CEO in May 1998. He has published over 150 papers in numerous international publications and holds six patents. He chairs and serves on various program committees of international conferences and on many editorial boards of scientific magazines. He has been the Guest Editor for special issues of Microelectronics Journal.

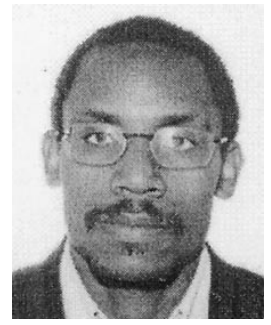

Fabien Ndagijimana received the Ph.D. degree from the Institut National Polytechnique de Grenoble (INPG), Grenoble, France, in 1990.

In 1990, he joined the faculty of Ecole Nationale Superieure d'Electronique et de Radioelectricite de Grenoble (ENSERG), Grenoble, France, as an Associate Professor of electromagnetism and microwave circuits and packaging. Since 1997, he has been a Professor at the Universit, Joseph Fourier de Grenoble, Grenoble, France. In the Laboratoire d'Electromagnétisme Microondes et Optoélectroniques (LEMO), Grenoble, France, he developed the transmission line matrix (TLM) method applied to the electromagnetic modeling of electromagnetic interference in high-speed and microwave circuits. His research activity includes modeling and characterization of microwave and RF devices, and the analysis of electromagnetic interference in high-speed IC's. 